\title{
Gestão de Marca: influências da hierarquia e arquitetura no posicionamento empresarial
}

Branding: influences of the hierarchy in the architecture and business position

GARCIA, Lucas José; Mestrando; Universidade Federal de Santa Catarina - UFSC

lucasjose@gmail.com

TEIXEIRA; Júlio Monteiro; Doutorando; Universidade Federal de Santa Catarina - UFSC

juliomontex@gmail.com

MERINO; Eugênio Andrés Diaz; Doutor; Universidade Federal de Santa Catarina - UFSC

merino@cce.ufsc.br

GONTIJO; Leila Amaral; Doutora; Universidade Federal de Santa Catarina - UFSC

leila@deps.ufsc.br

\begin{abstract}
Resumo
Além de identificar e corresponder demandas a organização deve também apresentar e posicionar os produtos de forma clara. $O$ artigo tem como objetivo compreender a gestão da marca sob os aspectos de hierarquia e arquitetura, e suas decorrências no posicionamento empresarial. A pesquisa, de natureza aplicada, foi dividida em duas etapas, a primeira teórica e de revisão sistemática e a segunda de caráter descritivo, por organizar, sistematizar e representar visualmente estruturas de hierarquia e arquitetura de marcas. Os resultados contemplam um modelo de distribuição hierárquica dos elementos do conjunto marca e a organização de modelos de arquitetura de marcas, reforçando que o desenvolvimento de uma marca deve ser planejado, prevendo sua extensão e relação com demais marcas e produtos da empresa.
\end{abstract}

Palavras Chave: Gestão de marca; Hierarquia de marca; Arquitetura de marca.

\begin{abstract}
Besides identifying and meeting demands, the organization must also present and position the products clearly. This paper aims to understand the brand management on the aspects of hierarchy and architecture, and their impacts on corporate positioning. The research, of applied nature, was divided in two stages, the first theoretical and of systematic review and the second of descriptive character, that organizes and visually represents structures of hierarchy and brand architecture. The results include a model of hierarchical distribution of elements of the brand and the organization of brand architecture models, emphasizing that the development of a brand must be planned, predicting its extent and relationship with other brands and products of the company.
\end{abstract}

Keywords: Branding; Brand Hierarchy; Brand Architecture.

\section{Introdução}

A imagem idealizada pela empresa nem sempre corresponde à imagem formada na 
Lucas J. Garcia; Júlio M. Teixeira; Eugenio A. D. Merino; Leila A. Gontijo

mente do consumidor. Neste sentido, orientar essa relação pode ser uma das funções da gestão da marca, pois quando ocorre uma dicotomia entre a imagem pretendida pela empresa e a imagem percebida pelas pessoas faz-se necessário rever sua imagem. Dessa forma, mostra-se importante apresentar e posicionar os produtos ${ }^{1}$ de forma clara e corresponder às demandas de consumo no que diz respeito ao processo produtivo e ao produto em si.

A marca tem um papel decisivo na percepção do produto, pois os consumidores percebem o produto moldado pela marca (TYBOUT; CALKINS, 2006). Gerenciar os elementos institucionais dentro do sistema de marca está entre as principais tarefas do gestor, pois é uma maneira básica de controle institucional.

Acredita-se que a hierarquização dos conceitos relacionados à gestão de marcas facilitam o alinhamento e posicionamento de elementos que identificam uma organização e/ou seus produtos. Entender a disposição destes conceitos também facilita a definição e estruturação de posicionamento empresarial por meio da arquitetura de marca. Portanto, o presente artigo tem como objetivo compreender a gestão da marca sob os aspectos de hierarquia e arquitetura, e suas decorrências no posicionamento empresarial.

A posse de uma grande variedade de marcas tornam dispendiosos os investimentos para sua manutenção, sendo em alguns casos, necessário reduzir o repertório e concentrar os investimentos para fortalecer o negócio (STRUNCK, 2007). Nesse sentido, Wheeler (2008) apresenta a estratégia adotada pela Unilever em 1999, ao reduzir seu portfólio de 1.600 para 400 marcas.

A razão dos supermercados estarem abarrotados de produtos e consequentemente de marcas, deve-se ao fato de mais de $90 \%$ dos lançamentos serem produtos derivados de uma marca principal (RIES; TROUT, 2009).

\section{Metodologia}

A pesquisa classifica-se como de natureza aplicada, pois objetiva o desenvolvimento de modelos visuais que organizem conceitos relacionados à gestão de marca. Segundo seus objetivos a pesquisa classifica-se como exploratória (GIL, 2008).

A pesquisa exploratória teve como procedimento técnico o levantamento bibliográfico, por meio do qual se buscou informações em livros nacionais, internacionais e artigos internacionais. Foram priorizados livros de autores consagrados a nível nacional e internacional. Para os artigos, foi realizada busca na base de dados SCIENCEDIRECT ${ }^{\circledR}$ considerando os últimos três últimos anos de publicação (2009-2011) com os termos brand, branding, design e brand architecture.

Dessa forma, esta primeira parte da pesquisa utilizou o método dedutivo, produzindo dados gerais relacionados aos objetivos da pesquisa. Portanto este estudo pode ser caracterizado como teórico, de revisão sistemática.

Posteriormente, assumiu caráter descritivo por organizar, sistematizar e representar visualmente estruturas de hierarquia e arquitetura de marcas, conforme explica Gil (2008, p. 28), pesquisas descritivas "visam descobrir a existência de associações entre variáveis". Para isso, os conceitos do conjunto marca foram organizados hierarquicamente por meio do Brand Target, e conceitos pertinentes ao relacionamento entre marcas foram organizados em grupos, cada um deles representados graficamente, e apresentados em uma tabela.

Projética Revista Científica de Design I Universidade Estadual de Londrina I V.2 I N.2 I Dezembro 2011 


\section{Gestão de marcas}

O termo marca, indica interação entre os sinais expressivos (formais e comportamentais) e a imagem da organização nas mentes das pessoas. Para Strunck (2007) a marca é como uma pessoa que teve sua personalidade cuidadosamente criada e desenvolvida, tal personalidade é forjada por meio de ações de comunicação do seu design, de sua publicidade, de seu comportamento social.

Tanto a familiaridade (número de experiências que um consumidor tem com o produto) quanto o conhecimento (capacidade de ter sucesso nas funções do produto) criam as distinções entre produtos dentro das categorias que são percebidas diferentemente pelos consumidores. Desta forma, a marca fornece ao produto e a organização um significado e uma história, e como um signo auxilia nas associações emocionais que são criadas na mente do consumidor (MOZOTA, 2003).

O gerenciamento de marca ou branding prevê o planejamento e implementação da marca, visando o desenvolvimento e o controle de suas diversas expressões, por meio da organização de ações estratégicas de construção e projeção no mercado (AAKER 2007). Assim, o trabalho contínuo de administração e divulgação podem gerar uma boa imagem da marca, atribuindo um valor afetivo e financeiro para tudo o que está ligado a ela (SOUSA, 2001).

Logo, mostra-se necessário alinhar sua essência, seu posicionamento e os elementos que a identificam, para isso, cabe ao gestor entender onde e como se comportam tais elementos dentro do sistema de marca. A partir da hierarquização dos conceitos de assinatura visual, identidade visual, identidade corporativa e marca, portanto, mostra-se importante alinhar a distribuição dos elementos que identificam e estruturam uma organização, com a finalidade de facilitar a gestão da marca e consequentemente seu posicionamento.

\section{Posicionamento}

Para Ries e Trout (2009), o posicionamento está relacionado ao produto, no entanto, não é algo feito no produto em si, mas na mente do consumidor, é a relevância e pregnância do produto na mente do cliente em potencial. Em contrapartida, segundo Souza e Nemer (1993), o posicionamento está condicionado à marca, pois é por meio desta que o consumidor visualiza o produto. Para Tybout e Calkins (2006) ambas as abordagens - posicionamento de produto e posicionamento de marca - se referem ao mesmo conceito. Segundo os autores, a marca influencia na forma como as pessoas vêem os produtos, raramente o consumidor percebe apenas o produto ou serviço, normalmente vêem o produto associado à marca, sendo os dois percebidos como uma única entidade, na percepção do consumidor, o produto está moldado pela marca.

Na visão de Strunck (2007), o posicionamento envolve uma série de variáveis: produto e/ou serviço; público-alvo; diferenciais competitivos; concorrência; vantagens; benefícios; percepções de qualidade e preço.

Conforme apresentado por Fuchs e Diamantopoulos (2010), o posicionamento de marca está relacionado a um fenômeno perceptivo e subjetivo de construção da imagem da marca pelo consumidor, formado por meio de uma interpretação racional ou emocional. Para Kotler (2010) o posicionamento está relacionado à marca, sua identidade e integridade. Nesse sentido, a identidade da marca corresponde ao seu posicionamento na mente dos consumidores e precisa ser relevante para suas necessidades e desejos. Enquanto a integridade da marca está 
Lucas J. Garcia; Júlio M. Teixeira; Eugenio A. D. Merino; Leila A. Gontijo

relacionada a concretização do que se alegou a respeito do posicionamento, corresponde a confiança transmitida e a satisfação do consumidor após a experiência com a marca.

Portanto, apoiados nos conceitos apresentados anteriormente por: Kotler (2010); Fuchs e Diamantopoulos (2009); Strunck (2007); Tybout e Calkins (2006) e Ries e Trout (2009), podese considerar que as variáveis condicionadas ao posicionamento devem estar em sinergia para garantir integridade à marca, garantindo coerência na percepção dos consumidores em relação ao conjunto empresa-produto-marca. Para Mozota (2011), as marcas são projetadas para atingir nichos específicos do mercado. O posicionamento é a fatia de mercado que a marca define para si no ambiente competitivo, e está relacionado à segmentação do públicoalvo.

Por meio do posicionamento as empresas podem transformar obstáculos em oportunidades, utilizando-se das mudanças que ocorrem em dados demográficos, na tecnologia, nos ciclos de marketing, nas tendências dos consumidores, nas brechas do mercado e assim, encontrar novos meios de destacar o produto entre os concorrentes, atraindo a atenção do público (WHEELER, 2008).

A imagem idealizada pela empresa nem sempre está em sintonia com a imagem formada na mente do consumidor, portanto avaliar sua imagem e posicionamento deve ser uma prática frequente do gestor de marcas. Fuchs e Diamantopoulos (2010) explicam que o posicionamento pretendido é como a empresa quer que a marca seja percebida pelos consumidores, enquanto o posicionamento real é de fato a percepção e o posicionamento aceito pelo consumidor.

A composição da imagem mental formada pelo receptor deveria retornar à empresa e ser confrontada com a que se desejava transmitir e com a imagem ideal que responderiam aos objetivos em longo prazo, reduzindo a diferença entre imagem ideal e o reflexo desta imagem (MARTINS; MERINO, 2008, p. 173).

A arquitetura de marcas possibilita manejar o mix de produtos da empresa de forma estratégica, novos produtos podem ser lançados com a mesma aceitação dos já consolidados. Estratégias de arquitetura de marcas permitem o posicionamento das marcas de acordo com os objetivos da empresa. Por meio dessas estratégias é possível fortalecer e potencializar o mix de produtos, gerando economias e lucros.

\section{Hierarquia de marca}

A assinatura visual é elemento central de um sistema de identidade visual. Possui função comercial, histórica e legal, e seu gerenciamento pode ser fator decisivo para o sucesso de uma organização. Além de identificar, também estabelece significação ao que faz referência, seja uma empresa, um território, um produto ou serviço, desta forma, pode construir maior identificação com seus clientes por meio de sua identidade. Então, por desenvolver e gerenciar, o design também atua de forma estratégica, concretizando identidade; fortalecendo marcas; e materializando culturas (AAKER, 2007); (DORMER, 1997); (MOZOTA, 2003). Símbolo.

Para Strunck (2007) é chamada assinatura visual a combinação do logotipo e símbolo. Neste texto entende-se pelo termo assinatura visual, o sinal gráfico distintivo de uma organização, produto ou proposta, composto pelo nome em grafia própria (lettering) e/ou símbolo (Figura 01). 


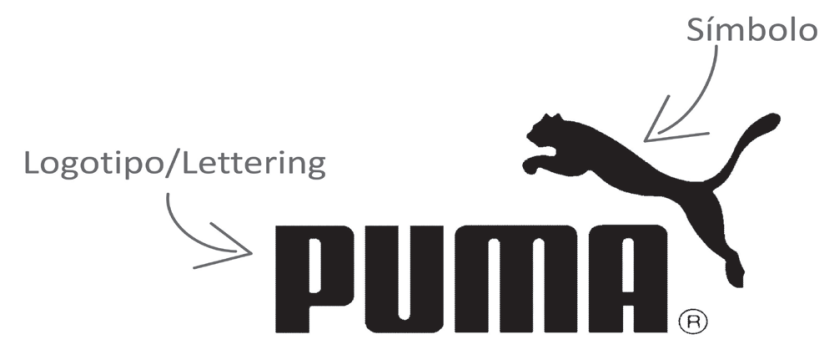

Figura 1- Assinatura Visual

Fonte: Adaptado de Puma² (2011)

Quando um nome ou idéia é representado visualmente sob determinada forma, podemos dizer que ele tem uma identidade. A identidade visual é o conjunto de elementos gráficos que irão formalizar a personalidade visual de um nome, idéia, produto ou serviço (STRUNCK, 2007).

O conjunto de elementos institucionais e as regras que irão reger suas aplicações chama-se Manual de Identidade Visual, que orienta a implantação e manutenção do sistema de identidade visual (STRUNCK, 2007). Portanto, a identidade visual reúne elementos institucionais que exploram prioritariamente o sentido da visão, enquanto elementos institucionais que exploram com maior intensidade outros sentidos pertencem a um conjunto mais abrangente denominado Identidade corporativa.

A identidade corporativa da empresa é formada pelo conjunto de todas as suas manifestações. Esse conjunto abriga os produtos, embalagens, folhetos, uniformes e procedimentos de atendimento, compostos com textos linguísticos, sonoros, visuais e comportamentais, dentre outros, que expressam o caráter da empresa e constituem sua marca (SOUSA, 2001).

A identidade corporativa não é formada apenas por um desenho, nome ou slogan. Tudo em uma empresa precisa estar integrado à sua identidade: valores, metas e compromissos. Produtos, serviços, atendimento, pessoas, produção, distribuição e afins fazem parte de um sistema de comunicação que é visto pelos consumidores como elementos de identidade da marca que eles escolheram comprar (MARTINS, 2006).

Desta forma, identidade corporativa é a imagem mental oficial, que a organização propõe, assim, seu planejamento pode minimizar distorções da imagem desejada pela empresa. O Brand book serve então como um guia de orientação que busca nortear a significação de pontos de contato (ou elementos institucionais) da organização, procurando direcionar a percepção das pessoas sobre valores, conceitos e benefícios associados aos elementos que compõem a marca. (AAKER, 2007); (GIMENO, 2000); (WHEELER, 2008).

A marca é um nome, normalmente representado por um desenho. Por meio de experiências reais ou virtuais, objetivas ou subjetivas vamos atribuindo valores específicos às marcas. Essas experiências, associadas aos seus benefícios emocionais levam a sua fidelização, facilitando as escolhas diárias por um produto (STRUNCK, 2007). Cabe ao designer trabalhar significado, elementos tangíveis, intangíveis e a diferenciação visual das marcas (WHEELER, 2008). Pode-se inferir então que marca é a imagem mental constituída pelo conjunto de valores atribuídos pelas pessoas com quem se relaciona de alguma forma.

Segundo Teixeira (2011, p. 51), "a distribuição hierárquica de elementos que identificam uma organização é dada por meio de conjuntos, são eles: assinatura visual; identidade visual; identidade corporativa; e marca, essa distribuição foi denominada de Brand Target", a representação visual deste modelo será apresentada nos resultados. 


\section{Arquitetura de marcas}

A arquitetura de marcas corresponde a uma abordagem de relação hierárquica entre as marcas de uma organização, determinando como a marca vai se relacionar com determinado produto, categoria, ou várias categorias, permitindo conciliar a necessidade dos consumidores com a logística de organização e lucratividade da empresa (CHAILAN, 2009). Dentro deste contexto Wheeler (2008) defende que a arquitetura de marcas refere-se à hierarquia de várias marcas existentes em uma empresa. Para a autora, o design da identidade da marca pode ajudar a empresa a crescer e vender com mais eficácia, por meio da ordem visual e diferenciação.

Tal eficácia mostra-se mais importante na aquisição e fusão de empresas, que em um considerável número de casos resulta na manutenção das marcas adquiridas, inclusive nos casos em que estas são concorrentes. O lançamento de um produto pode incitar a utilização de uma nova marca, ou a manutenção de uma existente junto à incorporação de slogans, denominações específicas, como premium e gourmet.

Segundo Chailan (2009), não existe um modelo único de arquitetura de marcas, sendo que os autores divergem quanto ao número de níveis e conceitos relativos à sua hierarquização. Para Mozota (2011) existem duas camadas principais: Marca Mãe e Marca do Produto. A Marca Mãe é a marca corporativa, que funciona como um abrigo para todos os produtos e serviços da empresa. Ou seja, a marca mãe é a única evidenciada no produto, que recorre à denominação de venda como forma de diferenciação. As empresas que utilizam a Marca do Produto como estratégia, omitem sua marca corporativa, recorrendo a marcas diferenciadas para cada produto ou serviço. Ambos modelos são apresentadas a seguir (Figura 2):
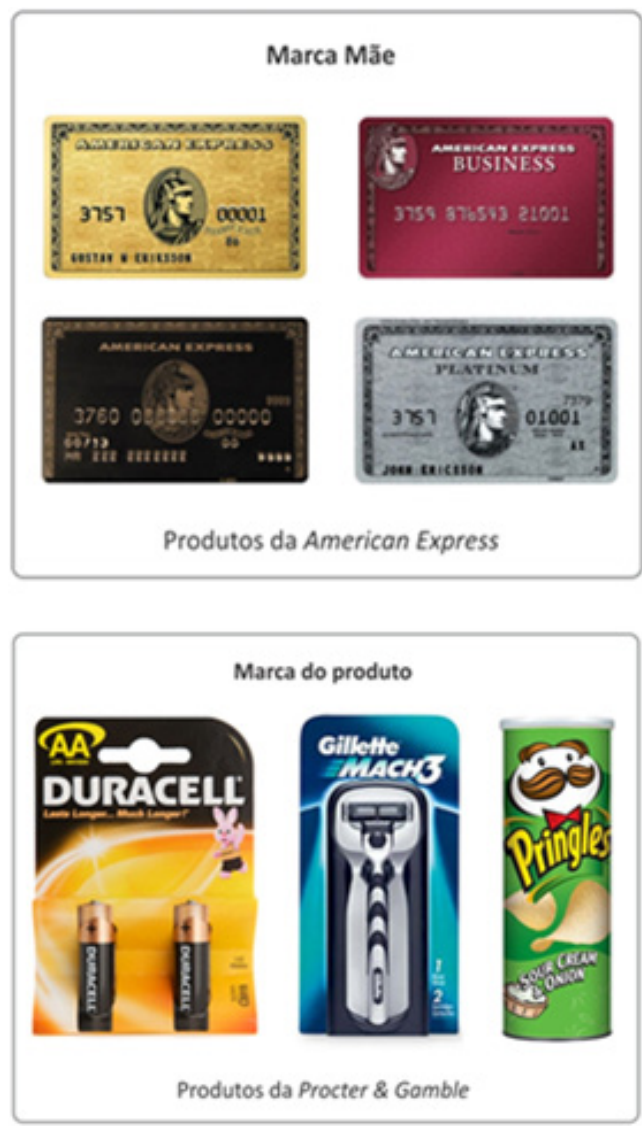

Figura 2 - Camadas principais da arquitetura de marcas

Fonte: Autor 
Gestão de Marca: influências da hierarquia e arquitetura no posicionamento empresarial

Wheeler (2008) apresenta quatro cenários para a arquitetura de marcas: (a) arquitetura de marca monolítica; (b) arquitetura de marca pluralística; (c) arquitetura de submarca; e (d) arquitetura de marca endossada.

(a) Marca monolítica: o consumidor confia na marca, priorizando-a em detrimento às características e benefícios do produto. Para aplicações nos produtos ou serviços são utilizadas denominações genéricas. Dentro deste cenário os consumidores tomam suas decisões baseados na fidelidade que tem pela marca, ao redor da qual tudo está unificado. Portanto, pode-se dizer que a única assinatura visual evidenciada no produto com registro legal é a marca mãe (ou marca corporativa), demais elementos textuais que sugerem a categoria a qual o produto pertence, mesmo que apresentados com grafia própria não são passíveis de registro legal, pois possuem nomes de uso comum, como por exemplo, sabão em pó.

(b) Marca pluralística: a empresa possui uma série de produtos com marcas conhecidas pelos consumidores. Os investimentos de marketing são direcionados ao público-alvo e visam promover as marcas dos produtos. A marca mãe pode ser desconhecida por parte dos consumidores, no entanto, é reconhecida primeiramente pelos empresários, sócios, acionistas e investidores.

(c) Marca subsidiária (ou arquitetura de sub marca): o produto ou serviço agrega a marca da empresa à sua marca, a marca mãe domina, entretanto as duas servem de condutoras. (d) Marca endossada: neste cenário a marca mãe endossa o produto ou serviço, mesmo estes possuindo público e presença de mercado bem definidos. Dessa forma o produto se beneficia com a associação da marca mãe.

As marcas podem abranger uma ou mais categorias. Dentro da concepção de Tybout e Calkins (2006), quando as marcas estão distribuídas entre produtos de uma mesma categoria são denominadas extensões de linha, enquanto marcas presentes em produtos de categorias distintas são designadas extensões de categoria. Strunck (2007), ao abordar as extensões de marcas, apresenta dois modelos de extensões de linhas: (a) verticais e (b) horizontais.

(a) Verticais: esse tipo de extensão de linha se caracteriza pela aplicação da marca de um produto em outros produtos da mesma categoria, podendo estes apresentar variação de preço e qualidade.

(b) Horizontais: nesse tipo de extensão de linha a marca é aplicada a produtos ou serviços de categorias diferentes. Essas aplicações devem levar em conta o conceito da marca mãe, para que suas qualidades e valores sejam transmitidos a toda a linha de produtos.

\section{Resultados}

O Brand Target (Figura 3), mencionado em Hierarquia de Marca, faz analogia a um alvo pela disposição de forma hierárquica, radial e fixa dos conjuntos - o conjunto menor pertence ao conjunto subsequente maior. A distribuição destes elementos institucionais é flexível (como dardos em um alvo), assim, a disposição de tais elementos é dada conforme o principal campo do sentido explorado (que pode ser diferente conforme o nível de interação do objeto com os cinco sentidos). Os elementos também podem estar dispostos em áreas limítrofes entre dois conjuntos (por exemplo: uma embalagem pode explorar em igual intensidade ou intensidade similar o sentido da visão e os demais sentidos). 


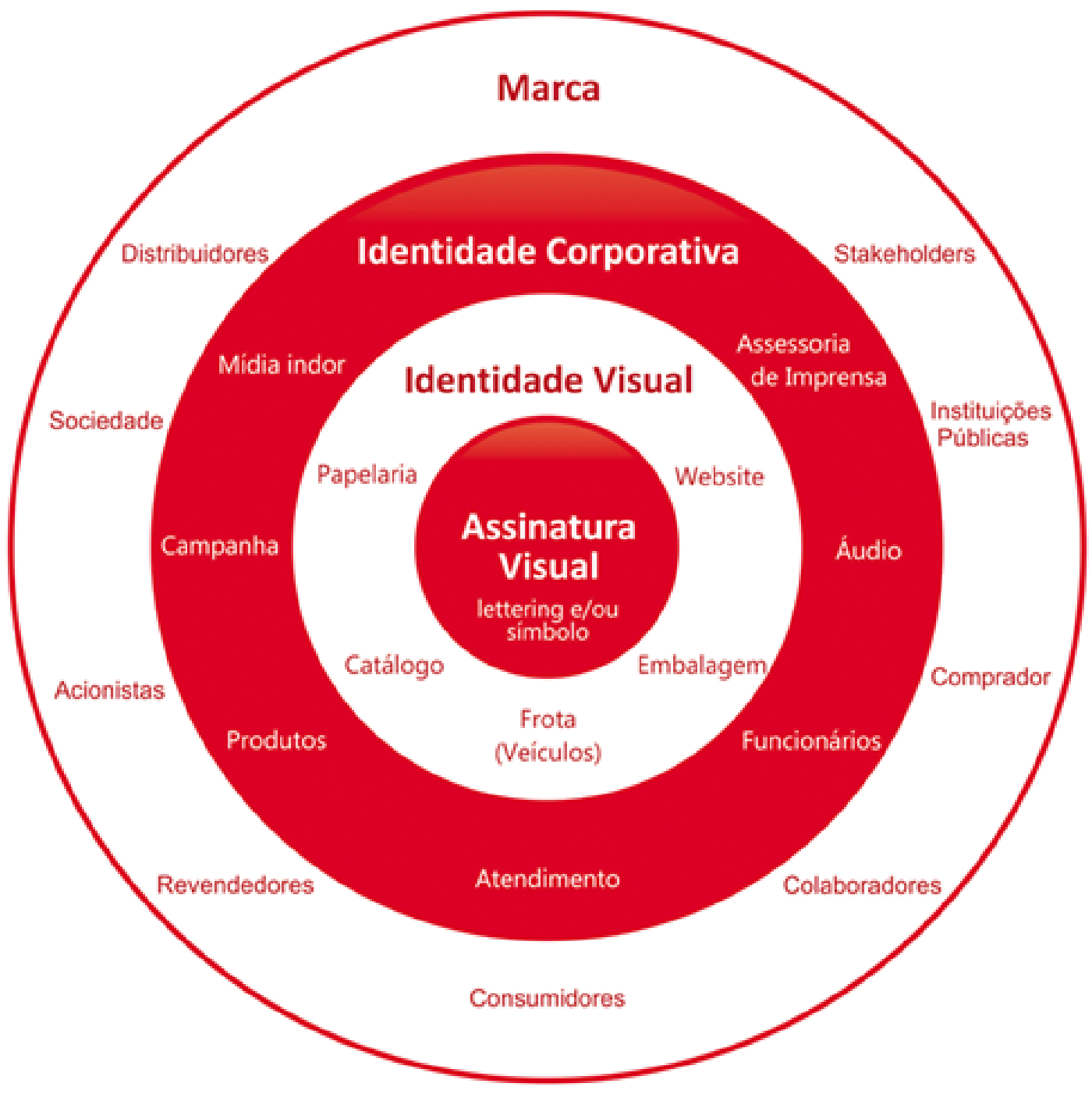

Figura 3 - Brand Target

Fonte: Teixeira (2011)

A partir do levantamento realizado, foram definidos três modelos de relacionamento para as marcas de uma organização:

a)Marca Mãe: representado por um conjunto, no qual os elementos correspondem aos produtos. Neste modelo os produtos são relacionados à marca mãe, que é normalmente a única percebida.

b)Marca do Produto: os elementos orbitam o conjunto (Marca Mãe). Embora pertençam a mesma organização, os produtos apresentam marcas próprias, ou seja, são elementos que não estão contidos no conjunto.

c)Marca Mãe e Marca do Produto: neste modelo, conjunto e elementos são sobrepostos. Embora uma das marca possa ser evidenciada, Marca Mãe e Marca do Produto são apresentadas.

d)A figura 4 apresenta esses modelos e objetiva à visualização dos conceitos levantados juntamente aos seus aspectos positivos, negativos e exemplos, permitindo assim uma comparação estratégica do modelo mais pertinente a cada realidade empresarial. 
Gestão de Marca: influências da hierarquia e arquitetura no posicionamento empresarial

\begin{tabular}{|c|c|c|c|c|}
\hline MODELO & DEFINIÇÃO & PRÓS & CONTRAS & EXEMPLOS \\
\hline Marca Mãe & $\begin{array}{l}\text { Os produtos apresentam } \\
\text { a marca măe (marca } \\
\text { corporativa) e } \\
\text { denominaçōes genéricas } \\
\text { para diferencia-los. }\end{array}$ & $\begin{array}{l}\text { Poucos investimentos } \\
\text { para promoçăo dos } \\
\text { produtos. Fortalecimento } \\
\text { da marca corporativa. } \\
\text { Economias com registro } \\
\text { de marcas de produtos. }\end{array}$ & $\begin{array}{l}\text { Problemas na imagem e } \\
\text { credibilidade da marca } \\
\text { podem interferir em } \\
\text { todos os produtos e na } \\
\text { imagem da corporaçăo. }\end{array}$ & $\begin{array}{c}\text { Virgin } \\
\text { Starbucks } \\
\text { American Express } \\
\text { BMW }\end{array}$ \\
\hline Marca do Produto & $\begin{array}{l}\text { Cada produto apresenta } \\
\text { uma marca própria, a } \\
\text { marca mãe pode ser } \\
\text { desconhecida pelo } \\
\text { público, e é conhecida } \\
\text { prioritariamente pelos } \\
\text { investidores. }\end{array}$ & $\begin{array}{l}\text { Investimentos podem focar } \\
\text { públicos alvo especificos. } \\
\text { Problemas com uma } \\
\text { marca/produto năo } \\
\text { interferem na imagem da } \\
\text { corporação. Permite o } \\
\text { desenvolvimento de valor de } \\
\text { cada marca. }\end{array}$ & $\begin{array}{l}\text { Tornam-se onerosos os } \\
\text { investimentos para } \\
\text { manutenção e publicidade } \\
\text { de várias marcas. } \\
\text { Restringe a percepção do } \\
\text { público quanto ao } \\
\text { potencial da coorporaçăo. }\end{array}$ & $\begin{array}{l}\text { P\&G } \\
\text { Unilever } \\
\text { Pepsico } \\
\text { Kraft }\end{array}$ \\
\hline $\begin{array}{c}\text { Marca Mãe e } \\
\text { Marca do Produto }\end{array}$ & $\begin{array}{l}\text { A marca mãe e a marca } \\
\text { do produto sð̆o } \\
\text { evidenciadas, podendo } \\
\text { uma receber mais } \\
\text { destaque de acordo com } \\
\text { os objetivos da empresa. }\end{array}$ & $\begin{array}{l}\text { Marca do produto pode } \\
\text { ser favorecida pela } \\
\text { imagem da marca mãe. } \\
\text { Aumento da sinergia } \\
\text { entre as marcas. Clareza } \\
\text { na oferta de produtos. }\end{array}$ & $\begin{array}{l}\text { Interferências negativas } \\
\text { em uma marca afetam a } \\
\text { integridade de outros } \\
\text { produtos e da empresa. }\end{array}$ & $\begin{array}{l}\text { Nestlé } \\
\text { Adobe } \\
\text { Apple }\end{array}$ \\
\hline
\end{tabular}

Figura 4- Organização dos conceitos de arquitetura de marcas

Fonte: Autor

A partir da figura 4, percebe-se que a arquitetura de marcas é parte integrante da gestão de marca, e contribui para a estruturação lógica dos produtos e marcas de uma organização, gerando mensagens claras que podem favorecer seu reconhecimento e valorização.

\section{Conclusão}

O Brand Target esclarece como se dá a hierarquia do conjunto marca ao facilitar o diagnóstico do estado atual de marca de uma empresa, ou seja, como está a distribuição hierárquica de elementos que identificam a organização nos conjuntos, e a partir de então, traçar estratégias de reposicionamento (planejar o estado futuro), focando diretamente na distribuição dos elementos institucionais (ou a distribuição dos dardos no alvo). Desta forma, a representação visual (alvo) do Brand Target facilita o entendimento. O Brand Target principalmente por meio de sua representação visual pode facilitar o entendimento da hierarquia do conjunto e dos subconjuntos da marca e, consequentemente, a distribuição de seus elementos.

A organização dos conceitos de arquitetura de marcas, juntamente com seus prós e contras, evidencia as diferenças de cada modelo, auxiliando no diagnóstico do modelo adotado por uma empresa para o alinhamento com seus objetivos, e proposta de soluções estratégicas de gestão de marcas.

As possibilidades de relacionamento entre marcas de uma mesma organização permite manejar o mix de produtos de uma empresa estrategicamente, assim, novos produtos podem ser lançados com maior aceitação, utilizando-se da credibilidade obtida pelos outros produtos já consolidados. Portanto, implicações estratégicas de marcas têm relação direta com o lançamento de novos produtos, quando se é necessário optar pelo lançamento de uma nova marca, ou o patrocínio de uma marca já existente (CHAILAN, 2009). 
Para a adoção de um modelo de arquitetura de marcas é pertinente uma avaliação e um planejamento das expectativas futuras da organização, para que a estratégia adotada sirva de plataforma para o crescimento da empresa. Dessa forma, não existe um modelo melhor de arquitetura de marcas, e sim, um modelo que melhor se adapte às características de uma empresa ou a seu mix de produtos.

Reconhecer a distribuição dos conjuntos facilita a coordenação dos elementos institucionais e consequentemente o gerenciamento da marca. No contexto empresarial, a abrangência e a importância da marca têm sido cada vez mais ampliadas, por ser considerado elemento fundamental nas estratégias de comunicação, administração e comércio de produtos e serviços. A marca não é depreciada pelo uso, ao contrário de outros ativos patrimoniais, ela é fortalecida quando seu uso é adequado, quanto mais for utilizada mais se fortalecerá. Dessa forma, a gestão de marcas é influenciada tanto pela hierarquia do conjunto marca, como pela gestão do relacionamento entre as marcas de uma organização.

Uma administração de marca ineficiente pode dificultar, por exemplo, que um produto seja associado à assinatura visual, aos demais produtos e a uma organização, ou ainda, ao lançar no mercado famílias de produtos, uma empresa de marca consolidada, pode errar por não planejar a distribuição dos elementos institucionais (dardos), isso pode ocasionar equívocos (os dardos podem atingir outros alvos), e assim confundir as pessoas com relação ao posicionamento da empresa e o posicionamento de seus produtos. Assim, hierarquia e a arquitetura podem facilitar a gestão de marca, quando trabalhadas de forma complementar, atribuindo sinergia, coerência e clareza entre os produtos e a organização.

\section{Notas}

${ }^{1}$ Neste texto entende-se por produto "algo que pode ser oferecido a um mercado para satisfazer uma necessidade ou desejo" (KOTLER, 2006, p. 366).

${ }^{2}$ Retirado do site oficial da PUMA, Brasil:<http://brasil.puma.com/>. Acesso em: 29 jun. 2011

\section{Referências}

AAKER, David A. Construindo marcas fortes. Porto Alegre: Bookman, 2007.

DORMER, Peter. Manual de gestão de design. Porto: Ed. Porto, 1997.

CHAILAN, Claude. Brand architecture and brand portfolio: a clarification. EuroMed Journal of Business, v. 4, n. 2, p. 172-184, 2009.

FUCHS, Christoph; DIAMANTOPOULOS, Adamantios. Evaluating the effectiveness of brandpositioning strategies from a consumer perspective. European Journal of Marketing. v. 44, $\mathrm{n}$ 11, p. 1763-1786, 2010.

GIL, Antonio Carlos. Como elaborar projetos de pesquisa. 4. ed. São Paulo: Atlas, 2002.

GIL, Antônio Carlos. Métodos e técnicas de pesquisa social. 6. ed. São Paulo: Atlas, 2008.

GIMENO, José Maria Ivañez. La gestión del diseño en la empresa. Madrid: McGraw Hill, 2000. 
Gestão de Marca: influências da hierarquia e arquitetura no posicionamento empresarial

KOTLER, Philip. Administração de marketing. 12. ed. São Paulo: Pearson Prentice Hall, 2006

KOTLER, Philip. Marketing 3.0: as forças que estão definindo o novo marketing centrado no ser humano. Rio de Janeiro: Elsevier, 2010.

MARTINS, José Roberto. Branding: um manual para criar gerenciar e avaliar marcas. São Paulo: Negócio, 2006.

MARTINS, Rosane Fonseca de Freitas; MERINO Eugenio Adrés Díaz. A gestão de design como estratégia organizacional. Londrina: EDUEL, 2008.

MOZOTA, Brigitte Borba de. Design Management: using design to build brand value and corporate innovation. New York: Allworth Press, 2003.

MOZOTA, Brigitte Borja de; KLÖPSCH, Cássia; COSTA, Filipe Campelo Xavier. Gestão do Design: usando o design para construir valor de marca e inovação corporativa. Porto Alegre: Bookman, 2011.

PUMA Brasil. Disponível em: <http://brasil.puma.com/> . Acesso em: 29 jun. 2011.

RIES, Al; TROUT, Jack. Posicionamento: a batalha por sua mente. São Paulo: M. Books do Brasil, 2009.

SOUSA, Richard Perassi Luis de . A visualidade das marcas institucionais e comerciais como campo de significação. 2001. 232 f. Tese (Doutorado) - Pontifícia Universidade Católica, São Paulo, 2001.

STRUNCK, Gilberto Luiz Teixeira Leite. Como criar identidades visuais para marcas de sucesso: um guia sobre o marketing das marcas e como representar graficamente seus valores. 3. ed. Rio de Janeiro: Rio Books, 2007.

TEIXEIRA, Julio Monteiro. Identificação e proteção: o design valorizando grupos produtivos de pequeno porte. 2011. 179 f. Dissertação (Mestrado em Design Gráfico) - Universidade Federal de Santa Catarina, Florianópolis, 2011.

TYBOUT, Alice M.; CALKINS, Tim (Org.). Branding: fundamentos, estratégias e alavancagem de marcas: implementação, modelagem e checklists: experiências de lideres de mercado. São Paulo: Atlas, 2006.

WHEELER, Alina. Design de identidade da marca: um guia completo para a criação, construção e manutenção de marcas. Porto Alegre: Bookman, 2008. 